\title{
AN INTEGRATED SERVICE EXCELLENCE MODEL FOR MILITARY TEST AND EVALUATION FACILITIES
}

\author{
Gerhard de Coning, Armscor, Pretoria \& Gerrit van der \\ Waldt, North-West University, Potchefstroom Campus
}

\begin{abstract}
The purpose of this article is to introduce an Integrated Service Excellence Model (ISEM) for empowering the leadership core of the capital-intensive military test and evaluation facilities to provide strategic military test and evaluation services and to continuously improve service excellence by ensuring that all activities necessary to design, develop and implement a test and evaluation service are effective and efficient. In order to develop the ISEM, various management tools and productivity and quality models were identified and tested through an empirical study conducted amongst the various test and evaluation facilities' leadership core. Solutions to financial, human resource and environmental challenges as well as quality standards were built into the ISEM. Governance principles and leadership perceptions and recommendations further contributed to the development of the ISEM.
\end{abstract}

\section{Orientation}

The Department of Defence (DoD) is mandated by the Constitution of the Republic of South Africa (Act 108 of 1996), the Defence Act (Act 42 of 2002), the White Paper on National Defence for the Republic of South Africa (1996) (referred to as "the White Paper") and the Defence Review (1998). These laws and policies direct and guide the functions of the DoD and the South African National Defence Force (SANDF). According to the White Paper, the services of an efficient defence industry are required to address the needs and constitutional obligations of the DoD. ${ }_{1}$ The cost-effective purchasing of products and systems and the life-cycle maintenance and support of such systems should be performed by the defence industry, whilst the capital-intensive military test and evaluation facilities (referred

Scientia Militaria, South African Journal of Military Studies, Vol 39, $\mathrm{Nr} 1,2011$, pp. 101-114. doi: $10.5787 / 39-1-104$ to as the "test and evaluation facilities") need to deliver effective and efficient test and evaluation services for retaining strategic defence capabilities and technologies. The test 
and evaluation facilities include the Weapon and Ammunition Test Range (Alkantpan) (a division of the Armaments Corporation of South Africa Ltd (Armscor) within the DoD), the Vehicle and Product Test Facility (Gerotek) (a division of Armscor within the DoD), the Overberg Missile Test Range (OTB) (a division of Denel (Pty) Ltd within the Department of Public Enterprises), the Paardefontein Explosives Facility (a division of the Council for Scientific and Industrial Research [CSIR] within the Department of Science and Technology), and the Paardefontein Antenna Test Range (a division of Armscor within the DoD). ${ }^{2}$

The problem to be addressed in this article, which is an abstract from a $\mathrm{PhD}$ study that was completed in 2009 at the North-West University, is how to ensure that the test and evaluation services provided by the test and evaluation facilities governed within the public entity domain are efficient and effective in meeting or exceeding the customer's requirements. Currently, various business and operational processes exist in these facilities without any common quality assurance and control and performance management systems. The purpose of this article is to introduce an ISEM for empowering the leadership core of the test and evaluation facilities to provide strategic military test and evaluation facility services and to continuously improve service excellence by ensuring that all activities necessary to design, develop and implement a test and evaluation service are effective and efficient. ${ }^{3}$ The model incorporates key concepts such as quality (defined as "conformance to requirements)", ${ }^{4}$ performance management (defined as "a process contributing to the effective management of individuals and teams to achieve high performance"), ${ }^{5}$ and service excellence (defined as "the perception of value elicited in the customer"). ${ }^{6}$

In order to develop the ISEM, various management tools for and approaches to improving quality were identified. Total Quality Management (TQM), Business Process Re-engineering (BPR), the South African Excellence Model (SAEM) and the Balanced Scorecard (BSC), amongst other productivity and quality models, were evaluated and tested through an empirical study conducted amongst the various test and evaluation facilities' leadership core.

Solutions to financial, human resource and environmental service excellence challenges facing the facilities were built into the ISEM, and applicable military, industrial and commercial quality standards and specifications were incorporated, such as the International Organisation for Standardisation (ISO) quality management standards and the Republic of South Africa (RSA) military standards. Corporate governance principles and leadership perceptions and management recommendations gathered in the empirical study further contributed to the development of the ISEM. 


\section{Research methodology and design}

A qualitative research design was followed and research was conducted amongst ninety per cent ( 90 per cent) of the management members of the facilities mentioned, as well as decision-makers in a governance workgroup of the SANDF. The viewpoints of all the respondents and their perceptions of their individual and team's knowledge, expertise and involvement in specific systems, principles and processes needed in the effective and efficient delivery of test and evaluation services, represent the overall view of the leadership core and decision-makers in the test and evaluation facilities mentioned, and of the SANDF workgroup. The measurement tool used in the research being reported here was an intervieweradministered questionnaire which was designed to obtain data from the abovementioned respondents. The questionnaire, for comparing information and data between theory on service excellence, governance principles and current performance indicators, was used to conduct a standardised interview with the said respondents at senior and top management level (the leadership core).

The results obtained from the semi-structured interviews were processed on MS Excel spreadsheet software, after which they were analysed, interpreted and summarised.

\section{Research findings: Analysis of empirical data}

The information received from the leadership core on quality management, performance management and challenges in obtaining service excellence is indicated below. $^{7}$

Biographic information

Figure 1 below indicates that the majority of respondents had more than 25 years' experience in government departments, more than 17 years' experience in military test and evaluation activities, and less than six years' experience in commercial test and evaluation activities. The level of experience in test and evaluation activities, corporate and public governance principles, performance measurement systems and involvement in solution-finding to management challenges within public entities constitutes a valuable contribution towards the development of the service excellence model. 


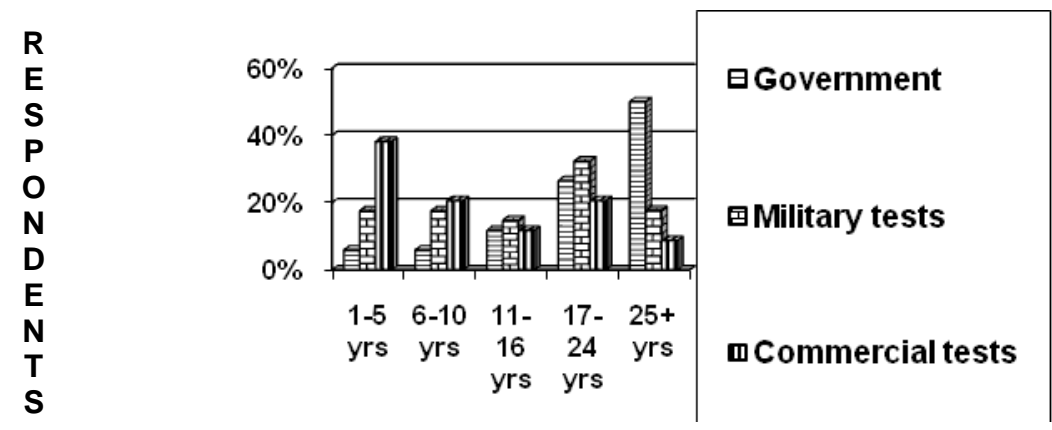

Figure 1: Years' experience ${ }^{8}$

Quality management

The TQM approach is regarded as the most suitable and useful approach (56 per cent on a ranking scale indicated by the respondents), followed by the systems thinking approach ( 23 per cent), BPR (17 per cent) and other ( 4 per cent) as depicted in Figure 2. A combination of the various approaches is used by most of the test and evaluation facilities.

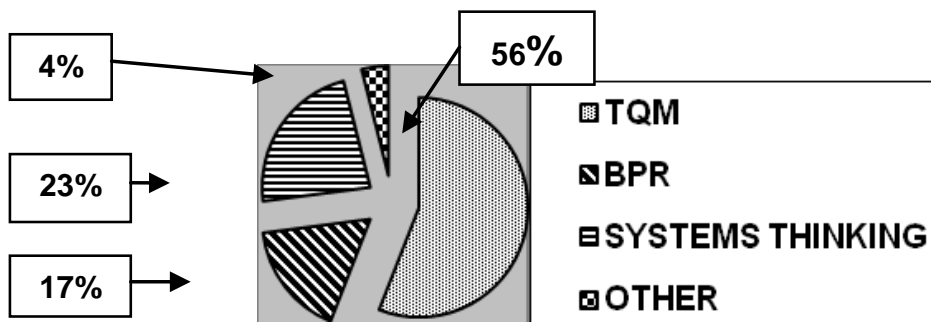

Figure 2: Quality management approaches ${ }^{9}$

Commitment and leadership from top management were identified and described as the first steps in quality management by the antecedents of modern quality management, such as Crosby, ${ }^{10}$ and echoed by modern quality specialists such as Oakland ${ }^{11}$ and Ross. ${ }^{12}$ The indication by the respondents of excellent engagement (41,2 per cent) from top management in commitment and leadership towards quality management, forms a good basis on which quality can be built in the test and evaluation facilities. As the improvement of services is regarded by Van der Waldt ${ }^{13}$ as a continuous, incremental and progressive process, the quality manage- 
ment approach of an entity should contribute to continuous improvement of services. The following suggestions were made for improvement towards quality management: ${ }^{14}$

- More effort is required to involve all personnel in quality management. Total quality must be introduced to all levels of employees and the importance of quality management must be clearly stated, e.g. by way of posters, surveys, information sessions.

- The quality management approach should improve its tools on knowledge management. Transfer and documentation of employee knowledge and capabilities through mentoring programmes or ongoing training are important. This knowledge and capability transfer should also be addressed in succession planning.

- Managers must be held accountable for the quality of services.

- Strategic needs from the customers on future developments should be requested to ensure that the necessary quality adjustments/requirements are attended to in order to adhere to changes in the market.

- Benchmarking against emerging and established best practices internationally is vital.

- Quality must be a lifestyle.

Performance management

Figure 3 indicates that the importance of the use of the BSC in the test and evaluation facilities is evident (50 per cent on a ranking scale indicated by the respondents). Elements of the SAEM (22,5 per cent) are used by the facilities, while some criteria of the performance prism (10 per cent) and Cambridge Performance Measurement System (5 per cent) are also in use.

For a performance management system to be effective, the performance indicators need to be linked and focused on the vision, strategic objectives and critical goals of the organisation. Eighty-five (85) per cent of the respondents agreed that this was the case. ${ }^{15}$ 


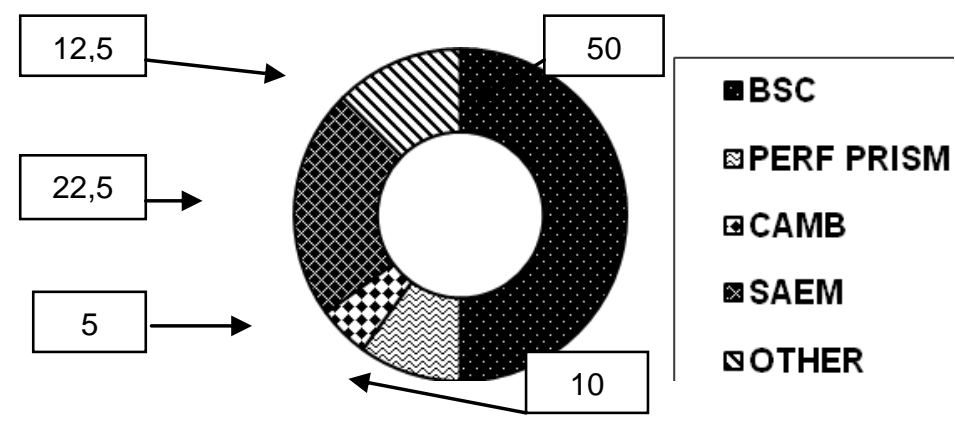

Figure 3: Performance management systems ${ }^{16}$

Oakland explains that participation in the development of measurement criteria by all employees enhances their understanding and acceptance of the measurement system, but the respondents indicated a negative situation at the test and evaluation facilities. ${ }^{17}$ Figure 4 reflects the extent to which the facilities' performance management systems allow employees' participation in the development of measurement criteria.

R
E
S
P
O
N
D
E
N
T
S

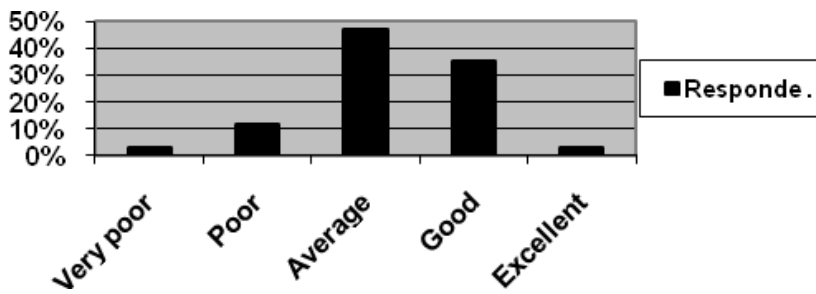

RATING

Figure 4: Participation in the development of measurement criteria $^{18}$

The following suggestions were made to improve the performance management system: ${ }^{19}$

- improve the involvement of employees at all levels in the development of the measurement criteria, where they need to envisage the link between their input and obtaining organisational objectives; 
- the performance management system should be integrated with the customer satisfaction surveys where customer inputs should be considered and implemented;

- the performance management system should allow inputs and criteria for strategic or emerging strategy planning in the medium to long term;

- performance rewards against the performance management system should be better aligned and larger differentiation should be applied in performance rewards between poor and excellent performers;

- the performance management system should find a balance between strategic and operational goals;

- there should be an enhanced focus on the strategic adjustments to be competitive in the ever-changing market, and the performance management system should be flexible to allow for changes at any point during a review period;

- quarterly instead of bi-annual performance review should be instituted, and regular feedback sessions are advised between managers and employees; and

- performance management should include the measurement of intangibles, such as loyalty to the organisation, willingness to accept responsibility and reaction to new challenges.

Challenges identified in obtaining service excellence

The importance and validity of challenges facing the test and evaluation facilities were tested against the viewpoints of the respondents and include: ${ }^{20}$

- sound business practices;

- knowledge of the King reports on Corporate Governance and Codes of Corporate Practices and Conduct (First report 1994; second report 2002; and third report 2009);

- knowledge of the Public Finance Management Act 1 of 1999 (PFMA) as amended and National Treasury regulations;

- in-time and accurate development of business and management information;

- broad-based black economic empowerment (BBBEE) initiatives;

- employment equity (EE) achievements;

- harmonious workplace relationships;

- development of human resources to achieve competitive advantage;

- safety, health and environmental (SHE) efforts;

- ISO or applicable standards accreditation; and 
- triple bottom-line success - prosperity, people, planet.

The test and evaluation facilities have to engage in sound public governance and corporate business practices in order to adhere to governance principles of accountability, economic prosperity, protection and sustainability of environmental resources, transparency of business management, as well as the creation of confidence in government and public administration. Control over strategy and management activities is needed in order to serve the needs of stakeholders.

The following comments or recommendations were made on service excellence in the testing and evaluation facilities: ${ }^{21}$

- increase the focus on employee, customer and supplier satisfaction improvement;

- establish and execute employee recognition for excellent service delivery;

- improve training methods and develop good mentors/trainers in order to promote good service excellence amongst the upcoming, young personnel;

- participation of every employee in service delivery improvement actions is needed, and employees must exploit their full potential to the benefit of the organisation;

- consistency in service delivery will enhance improved service excellence;

- a healthy environment should be created and maintained and more emphasis should be put on the management of HIV/AIDS;

- service excellence should be a key focus area in the planning and target setting of the facilities, with continuous improvement as a prime drive;

- the compliance of all facilities with the relevant ISO accreditation is a must and the relevant accreditation standards and norms must be incorporated into one integrated quality management system;

- extend services and/or facilities to accommodate new customer requirements and testing against new standards; and

- in order to improve efficiency, effectiveness and adaptability of services provided, all processes and management disciplines should be integrated into a quality model.

The objective was to incorporate the above-mentioned empirical findings and suggestions in the Integrated Service Excellence Model, which will be briefly outlined next. 


\section{Integrated Service Excellence Model}

The main objective of the Integrated Service Excellence Model (ISEM) is to evaluate an entity against all the business elements as indicated in Figure 5. The self-assessment should be done by the senior and middle management of the entity after which improvement action plans need to be compiled, implemented and measured in order to fulfil the purpose of striving towards service excellence. ${ }^{22}$

The self-assessment is done through a 7-point Likert-type scale questionnaire $(1=$ Not at all; $2=$ Very poor; $3=$ Poor; $4=$ Satisfactory; $5=$ Good; $6=$ Very good and $7=$ Excellent) on the following elements which summarise the ISEM:

- As the vision and mission (A1) indicate constancy of purpose and longterm success of an organisation, ${ }^{23}$ the first business element to be measured is the extent to which the vision and mission statements of the test and evaluation facility address the purpose and long-term success of the facility in a challenging way. This is followed by the extent to which all strategies (A2) are developed for specific challenges facing the test and evaluation facility and the extent to which these strategies are understood by the management team and all employees as well as the extent to which management conduct and behaviour are successfully focusing on the objectives (A3) which should be aligned with the strategies and mission of the facility.

- Governance (B1) ensures that the needs of customers are served efficiently, effectively and fairly through the provision of clear processes and structures on decision-making, strategic alignment, managerial control, supervision and accountability. ${ }^{24}$ These actions need to be measured in order to determine to what extent the management function (B2) is executed so that all activities of the test and evaluation facility address governance principles and business challenges in an objective way and to lead the facility to constant improvements (C1) in service delivery. Service delivery improvement is a continuous, incremental and progressive process. ${ }^{25}$

- The extent to which the integrated quality management system (C2) addresses services which are provided in a quality-centred approach, aiming at long-term success through customer satisfaction and benefits to all employees should be evaluated and measured. Integrated quality management incorporates various quality management models, tools and 
approaches in a system to improve quality in the total supply chain and life cycle of the product or service. ${ }^{26}$

- Measurement is needed of the extent to which all financial challenges (D1) and human resource challenges (D2) are addressed in the relevant strategies and plans as required by law (PFMA and Employment Equity Act) and stakeholder expectations, in order to mitigate the relevant risks involved. Measurement of the Safety, Health and Environmental (SHE) strategies and action plans (D3) is vital to improve sustainable development of economic prosperity, socio-political expectations (social well-being) and ecological needs (healthy environment). Occupational Health and Safety (OHS) is a cross-disciplinary area concerned with protecting the safety, health and welfare of employers, employees, family

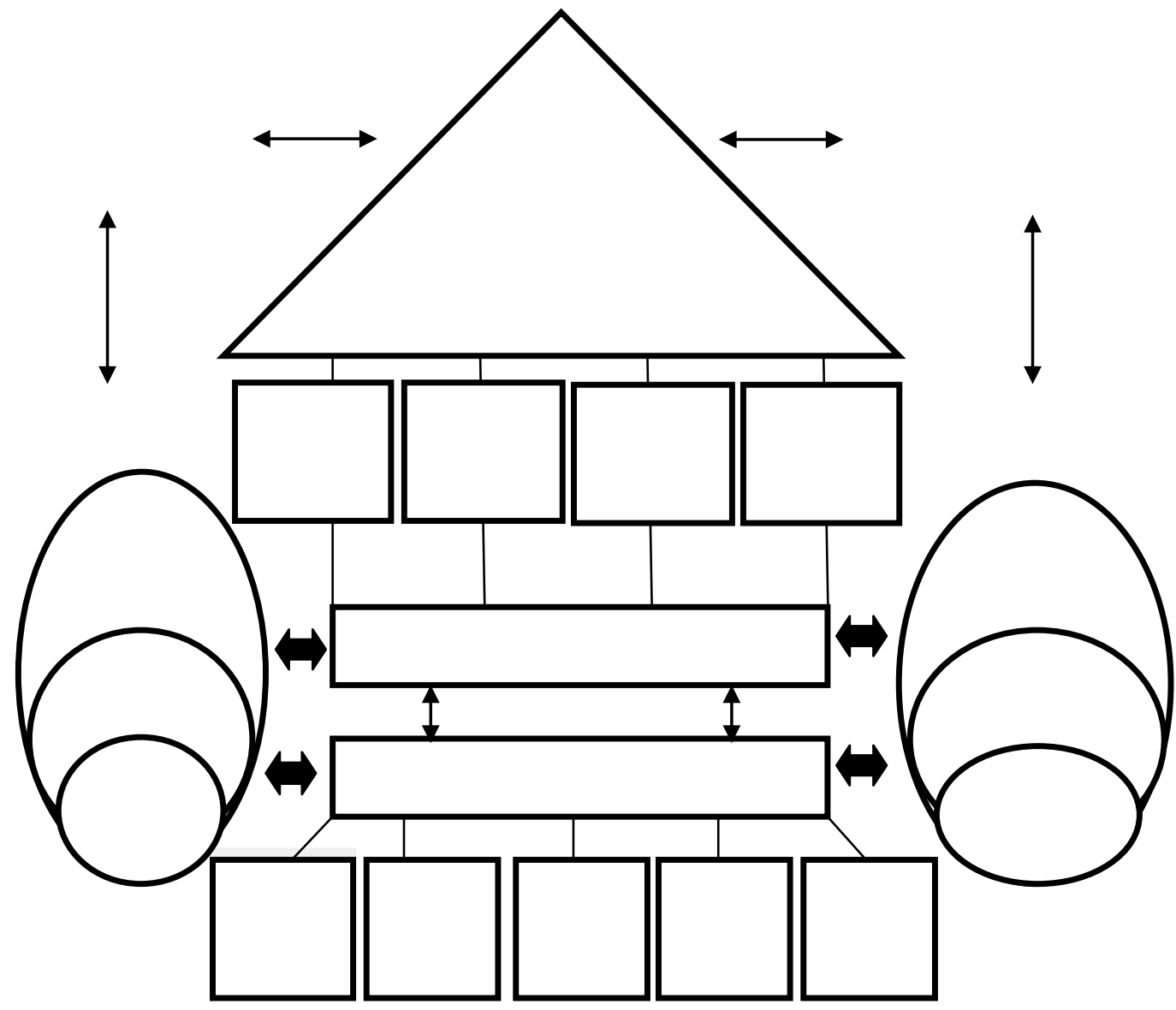


Figure 5: Integrated Service Excellence $\operatorname{Model}^{27}$

- members, customers, suppliers, nearby communities and other members of the public who are impacted by the workplace environment. ${ }^{28}$

- Evidence is to be measured of action plans to achieve and maintain accreditation for specific test standards and specifications (D4), including the RSA military standards and the ISO standards, as well as action plans to update and improve processes and test and evaluation services executed in the operational phase (E1) of service delivery.

- It is necessary to measure the extent to which the performance management system (F1) focuses on critical goals that bring visible progress on and the enhancement of how the facility uses available resources to deliver service excellence. This includes, amongst other things:

- the measurement of the way the financial indicators impact on financial stability (F2);

- the way the processes impact on operational excellence (F3);

- the way the customers' satisfaction levels are improved (F4);

- the way the investment in employees (F5) is measured to ensure improvement in skills in order to improve operating efficiencies and customer satisfaction; and

- the extent to which best practices and best-in-class organisations are identified and measured against all relevant best practises and organisations as identified (F6). ${ }^{29}$

- Measurement of the extent to which measurement surveys were implemented and conducted amongst all stakeholders (employees, customers, suppliers and shareholders), in order to gain useful information.

- Stakeholder delight (G1 and G2). The protection of stakeholder interests is embedded in sound organisational governance and effective relationships with stakeholders and a necessity for operational and service excellence (G3). ${ }^{30}$

The ISEM scores form the reference baseline from which future improvements will be measured. It is important that the test and evaluation facilities do not compare themselves with each other, as the ISEM tool indicates the selfassessment by the respective management teams in the specific environment. The objective is to improve the business elements and processes through the 
improvement action plans which need to be included in the total business plans of the test and evaluation facilities. Follow-up assessments are needed on an annual basis.

\section{Recommendations for implementing the Integrated Service Excellence Model}

The following recommendations can be made for implementing the ISEM in order to obtain and continuously improve excellence in services provided to the DoD by the test and evaluation facilities: ${ }^{31}$

- systematic implementation of the ISEM after self-assessment by senior and middle management. A follow-up assessment is needed after a period as decided upon (12 months regarded as a practical period);

- involvement of all personnel in the implementation and operation of the mode;

- detailed explanation of all the theoretical pillars, systems, processes and elements in the model through introductory training sessions;

- sharing with all employees the practical suggestions or recommendations for improvement towards service excellence made by the respondents;

- the development, training and mentoring of "champions" on specific systems or elements in the model, such as the developers of strategies and objectives, benchmarking specialists, quality management specialists, performance management specialists, corporate governance specialists and liaison specialists with shareholders, customers and employees;

- in order to fulfil the above-mentioned recommendations, a detailed project plan is needed for the implementation and operation of the integrated service excellence model; and

- as a future project, this ISEM needs to be programmed as an integrated computerised system in order to achieve effective and efficient use in the operational application of the model. Funding for such a project should be negotiated through the Secretariat for Defence by means of the Medium Term Expenditure Framework.

The above-mentioned recommendations will contribute to ensuring that all activities necessary to design, develop and implement a test and evaluation service are effective and efficient.

\section{Conclusions}


The purpose of this article was to report on findings obtained through a qualitative research study in order to develop an ISEM for the purpose of empowering the leadership core of the test and evaluation facilities in order to provide efficient and effective strategic military test and evaluation services and to continuously improve service excellence. Suggestions for the implementation of the model were also made.

Although the ISEM was developed in and for the military test and evaluation facilities, the application of the model by the leadership core is also viable for other service delivery departments, both in the public and private sector, in order to add citizen value.

${ }^{1}$ South Africa. Department of Defence. White paper on National Defence for the Republic of South Africa. 1996. <http://www.mil.za.Articles\& Papers/Papers/WhitePaperonDef/white.htm> Accessed on 22 June 2004.

${ }^{2}$ De Coning, GL. "An integrated service excellence model for strategic military test and evaluation facilities: The case of the South African National Department of Defence". Unpublished Phd dissertation. North-West University, 2009, 1.

${ }^{3}$ Ibid. p. 5.

${ }^{4}$ Crosby, PB. Quality without tears: The art of hassle-free management. New York: McGraw-Hill, 1984, 58.

5 Armstrong, M \& Baron, A. Performance management. 2008. <http://www.cipd.co.uk/subjects/perfmangmt/general/perfman.htm> Accessed on 18 February 2008.

${ }^{6}$ Shonhiwa, S. Signposts to service excellence: The African paradigm. Pretoria: Unisa Press, 2001, 32.

${ }^{7}$ De Coning, op. cit.

${ }^{8}$ Ibid.

${ }^{9}$ Ibid.

${ }^{10}$ Crosby, PB. Quality is free: The art of making quality certain. New York: McGraw-Hill, 1979, 132-139.

${ }^{11}$ Oakland, JS. Total quality management: Text with cases. $3^{\text {rd }}$ ed. Oxford: Elsevier Butterworth-Heinemann, 2003, 39-40.

${ }^{12}$ Ross, JE. Total quality management: Text, cases and readings. $2^{\text {nd }}$ ed. Florida: St. Lucie Press, 1995, 34.

${ }^{13}$ Van der Waldt, G. "Organisational profiling as foundation for service delivery baseline analysis". Journal of Public Administration 42/7. 2007. 622-637.

${ }^{14}$ De Coning, op. cit. pp. 101-102.

${ }^{15}$ Ibid. p. 103.

${ }^{16}$ Ibid. 
${ }^{17}$ Oakland, op. cit. p. 125.

${ }^{18}$ De Coning, op. cit.

${ }^{19}$ Ibid. pp. 106-107.

${ }^{20}$ Ibid. p. 108.

${ }^{21}$ Ibid. pp. 116-117.

${ }^{22}$ Ibid. p. 123.

${ }^{23}$ Oakland, op. cit. pp. 39-40.

${ }^{24}$ Deloitte. Governance. 2008. <http://www.deloitte.com/dtt/section_node/ 0,1042,sid\%253 D67114,00.html> Accessed on 3 March 2008.

${ }^{25}$ Van der Waldt, op. cit.

${ }^{26}$ De Coning, op. cit. p. 130.

${ }^{27}$ De Coning, op. cit.

${ }^{28}$ North-West University. General SHEQ management principles and concepts.

Centre for Environmental Management, North-West University, 2007.

${ }^{29}$ De Coning, op. cit. pp. 136-139.

30 Kaplan, RS \& Norton, DP. "Transforming the balanced scorecard from performance measurement to strategic management: Part 1". American Accounting Association 15/1. 2001. 93.

${ }^{31}$ De Coning, op. cit. p. 142. 